\title{
Electrophoretic separation and differentiation of enzymes from human and from porcine liver
}

\author{
D. N. BARON AND J. E. BUTTERY \\ From the Department of Chemical Pathology, Royal Free Hospital School of Medicine, London
}

SYNOPSIS The electrophoretic separations of some human and pig liver enzymes on cellulose acetate and Cellogel were investigated, with reference to their joint occurrence in serum of patients undergoing treatment by extracorporeal pig liver perfusion. In every case it was possible to distinguish between the human and pig enzymes. Pig lactate dehydrogenase isoenzymes occupy a position slightly anodic to the corresponding human bands. The aspartate transaminase band of human is more anodic than that of pig, but their cathodic bands have the same mobility. Alanine transaminase of both human and pig liver extract is shown to exist as two bands each towards the anode. The faster moving human band is more anodic than the corresponding pig band, while the other human band is less anodic. Sorbitol dehydrogenase, alkaline phosphatase, and ornithine carbamoyltransferase all exist as one band each. Human sorbitol dehydrogenase is more cathodic than the pig enzyme, human alkaline phosphatase more anodic than the pig enzyme, while human ornithine carbamoyltransferase is less anodic than the pig enzyme.

During work on the plasma enzyme changes both in patients with acute liver failure who undergo treatment by extracorporeal perfusion through isolated pig livers (Eiseman, 1966) and experimentally during isolated pig liver perfusion (Abouna, Ashcroft, Hull, Hodson, Kirkley, and Walder, 1969) it was necessary to utilize or develop methods for the independent demonstration in plasma of the enzymes originating from pig and from human tissues. As enzyme changes reflect liver cell integrity, we have assessed the pig liver damage during the extracorporeal perfusion (Buttery, Parbhoo, and Baron, 1971: preliminary communication).

In an experimental perfusion the plasma enzymes are derived from three possible sources: the priming normal human blood plasma with low enzyme values, human erythrocytes, and pig liver. In a clinical perfusion the same three enzyme sources are present, in addition to the patient's blood plasma with high enzyme values from the patient's diseased liver. During the course of perfusion the circulating blood invariably undergoes haemolysis which liberates erythrocyte enzymes into the circulation, raising the enzyme levels, thus making meaningful interpretation of liver damage difficult (Abouna et al, 1969). A poor isolation technique results in damage Received for publication 20 December 1971. to the pig's liver. Total enzyme assays do not distinguish the three main tissue sources-human erythrocytes, human liver, and pig liver: to overcome this problem it is necessary to use isoenzyme techniques. Fortunately the isoenzymes of pig and human liver enzymes can usually be distinguished by electrophoresis.

The isoenzymes investigated are those of lactate dehydrogenase (L-lactate: NAD oxidoreductase, EC 1.1.1.27), aspartate transaminase (L-aspartate: 2-oxoglutarate aminotransferase, EC 2.6.1.1.), alanine transaminase (L-alanine: 2-oxoglutarate aminotransferase, EC 2.6.1.2.), sorbitol dehydrogenase (L-iditol: NAD oxidoreductase, EC 1.1.1.14.), ornithine carbamoyltransferase (carbamoylphosphate: L-ornithine carbamoyltransferase, EC 2.1.3.3.), and alkaline phosphatase (orthophosphoric monoester phosphohydrolase, EC 3.1.3.1.). These enzymes are present in the liver, and their activities in plasma are commonly measured and used diagnostically in various liver diseases.

\section{Materials and Methods}

The investigation into the separation and differentiation of enzymes from human and porcine liver was done on $10 \% \mathrm{w} / \mathrm{v}$ liver extract in physiological 
$(0.9 \%)$ saline, except for alkaline phosphatase which required butanol extraction (Morton, 1955). The separation was by electrophoresis on cellulose acetate, this being a simple and rapid procedure, readily available in all hospital chemical pathology laboratories.

Cellulose acetate strip (Celagram: Shandon) size $78 \times 150 \mathrm{~mm}$ is convenient and four samples can be separated at a time. Gelatinized cellulose acetate (Cellogel: Chemetron-Milan) size $57 \times 140 \mathrm{~mm}$ is also used where indicated in the text and can take three samples. Electrophoresis is carried out in a Shandon electrophoresis tank with a Vokam power pack.

LACTATE DEHYDROGENASE

The procedure is drawn largely from Myers and Van Remortel (1968).

\section{Stock buffers}

(1) Barbitone, pH 8.6. Dissolve $2.76 \mathrm{~g}$ diethylbarbituric acid and $15.4 \mathrm{~g}$ sodium diethylbarbiturate in 1 litre deionized water.

(2) Tris- $\mathrm{HCl} 0.2 \mathrm{M}, \mathrm{pH} \mathrm{8.3:} \mathrm{dissolve} 24.2 \mathrm{~g}$ tris in about $800 \mathrm{ml}$ water. Add concentrated $\mathrm{HCl}$ to $p \mathrm{H} 8.3$ and dilute to 1 litre with water.

\section{Tank buffer}

Tris-barbitone, $p \mathrm{H} \mathrm{8.4.} \mathrm{Mix} \mathrm{equal} \mathrm{volumes} \mathrm{of} \mathrm{both}$ the stock buffers.

\section{Medium}

Cellulose acetate (Celagram) soaked in tank buffer.

\section{Electrophoretic run}

$175 \mathrm{~V}$ for one and a half hours.

\section{Enzyme locating reagent}

This is prepared just before electrophoresis is terminated. $25 \mathrm{ml} 0.2 \mathrm{M}$ tris- $\mathrm{HCl} p \mathrm{H} 8.3$ is added to $20 \mathrm{mg}$ NAD and $18 \mathrm{mg}$ MTT tetrazolium (Sigma). When dissolved add $2 \mathrm{ml} 1.0 \mathrm{M}$ sodium lactate solution and a pinch (about $1 \mathrm{mg}$ ) phenazine methosulphate (PMS). Soak a thick filter paper (Postlip: Evans, Adlard \& Co. Ltd: Cheltenham) in this solution and place it in a plastic box The cellulose acetate is cut to a manageable size and carefully floated on the substrate mixture for $\mathbf{3 0}$ seconds, after which it is gently lowered on the Postlip avoiding any trapped air. The box is covered and incubated at $37^{\circ} \mathrm{C}$ for 15 to 30 minutes, by which time lactate dehydrogenase bands appear. The strip is removed, washed in water, then in $5 \%$ acetic acid and with water again, and will keep at this stage in the refrigerator for a few days.
ASPARTATE TRANSAMINASE

The procedure is a modification of the method of Romel and LaMancusa (1965).

Stock enzyme substrate

Dissolve $10.05 \mathrm{~g} \mathrm{~K}_{2} \mathrm{HPO}_{4}$ and $300 \mathrm{mg} \mathrm{KH}_{2} \mathrm{PO}_{4}$ in $150 \mathrm{ml}$ water. Into this solution is now dissolved $220 \mathrm{mg} \alpha$-oxoglutarate and $800 \mathrm{mg} \mathrm{L}$-aspartic acid and finally $3 \mathrm{~g}$ polyvinyl pyrrolidone and $300 \mathrm{mg}$ disodium EDTA. Store at $4^{\circ} \mathrm{C}$.

\section{Stock buffer}

Barbitone $p \mathrm{H}$ 8.6. Dissolve $10.8 \mathrm{~g}$ sodium diethyl-융 barbiturate and $1.5 \mathrm{~g}$ diethylbarbituric acid in 1 litre deionized water.

\section{Tank buffer}

Dilute stock buffer with an equal volume of water.

\section{Medium}

Cellogel. Soak for at least one hour or overnight in the stock buffer.

\section{Electrophoretic run}

$150 \mathrm{~V}$ for one and a half hours.

\section{Enzyme locating reagent}

(1) Prepare just before termination of electro- $\frac{2}{\varnothing}$ phoresis. Heat $700 \mathrm{mg}$ Oxoid Ionagar no. 2 in $20 \mathrm{ml}$ water with constant stirring until the mixture boils. Cool to $60^{\circ} \mathrm{C}$, add $10 \mathrm{ml}$ stock enzyme substrate, followed by $1 \mathrm{ml}(60 \mathrm{mg})$ Fast violet $B$ salt. The mixture is poured into a shallow tray and allowed to solidify. The Cellogel is cut $3 \mathrm{~cm}$ either side from the origin and placed face downwards on the substrate gel avoiding trapped air. The tray is covered and incubated at $37^{\circ} \mathrm{C}$ for 20 to 30 minutes, by which $\delta$ time reddish bands appear. The Cellogel is washed in 3 water, in $5 \%$ acetic acid, and in water again. When o left at $4^{\circ} \mathrm{C}$ the Cellogel keeps for a few days.

\section{Enzyme locating reagent}

(2) Heat $700 \mathrm{mg}$ Ionagar in $20 \mathrm{ml}$ water as before. $\stackrel{\sim}{\circ}$ Add $10 \mathrm{ml}$ stock enzyme substrate containing $8 \mathrm{mg}$ N of newly added NADH and $0.03 \mathrm{ml}$ malate dehydro-N genase $(5 \mathrm{mg} / \mathrm{ml}-$ Boehringer Mannheim $\mathrm{GmbH})$ O when the agar solution is at about $60^{\circ} \mathrm{C}$. The mixture is poured into a shallow tray and allowed to solidify. $\frac{\mathrm{C}}{\Phi}$ The Cellogel is layered as previously described and $\stackrel{?}{?}$ left at room temperature for $\mathbf{1 5}$ minutes or longer.

Meanwhile another gel is prepared by heating $700 \mathrm{mg}$ Ionagar in $20 \mathrm{ml}$ water. When cooled to $\mathbb{\circ}$ $60^{\circ} \mathrm{C}, 10 \mathrm{ml}$ solution containing MTT $(10 \mathrm{mg})$ and $\overrightarrow{\mathrm{D}}$ PMS (1 mg) is added. Solidify in a shallow tray in the $\frac{\circ}{\sigma}$ dark. The above Cellogel is now layered on this second gel and left for $\mathbf{1 5}$ minutes in the dark at room 
temperature. By this time, the zone of enzyme activity is seen as a white band against a purplish blue background. Wash Cellogel as before and it will keep for several days at $4^{\circ} \mathrm{C}$.

\section{ALANINE TRANSAMINASE}

The electrophoretic procedure is similar to that for aspartate transaminase.

\section{Stock enzyme substrate}

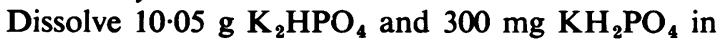
$150 \mathrm{ml}$ water. Into this solution is now dissolved $220 \mathrm{mg} \alpha$-oxoglutarate and $1.08 \mathrm{~g}$ alanine and finally $3 \mathrm{~g}$ polyvinyl pyrrolidone and $300 \mathrm{mg}$ disodium EDTA. Store at $4^{\circ} \mathrm{C}$.

\section{Enzyme locating reagent}

The method is basically similar to that for aspartate transaminase method 2, except that $0.03 \mathrm{ml}$ lactate dehydrogenase (Boehringer) is added instead of malate dehydrogenase.

\section{SORBITOL DEHYDROGENASE}

The procedure uses the phosphate-tris buffer of Hof, Wolf, and Krone (1969) and is adapted for Cellogel.

\section{Stock buffer}

$0.1 \mathrm{M}$ phosphate-tris buffer, $p \mathrm{H} 6.5$. To $500 \mathrm{ml} 0.2$ $M \mathrm{NaH}_{2} \mathrm{PO}_{4} \cdot 2 \mathrm{H}_{2} \mathrm{O}$ solution add $0.2 \mathrm{M}$ tris solution (about $200 \mathrm{ml}$ ) to adjust the $p \mathrm{H}$ to $6 \cdot 5$. Make up to 1 litre with deionized water.

\section{Tank buffer}

Dilute stock buffer five fold to $0.02 \mathrm{M}$ with deionized water.

\section{Medium}

Cellogel, soaked for at least one hour in the tank buffer.

\section{Electrophoretic run}

$150 \mathrm{~V}$ for one and a half hours.

\section{Enzyme locating reagent}

Prepare before the termination of electrophoretic run. Bring to gentle boil $20 \mathrm{ml} 0 \cdot 1 \mathrm{M}$ triethanolamine pH 8.2 and $700 \mathrm{mg}$ Ionagar. When cooled to about $60^{\circ} \mathrm{C}$ add the following: sorbitol solution $(800 \mathrm{mg} /$ $5 \mathrm{ml}$ buffer), solution of MTT and PMS (15 mg MTT/ $5 \mathrm{ml}$ buffer, and $1 \mathrm{mg}$ PMS), and NAD solution $(25 \mathrm{mg} / \mathrm{ml}$ buffer). Set gel in a shallow tray. Cut Cellogel to a suitable size and gently place it face downwards on the substrate gel, cover the tray, and incubate for $37^{\circ} \mathrm{C}$ for 20 to 30 minutes until blue bands appear. The Cellogel is washed and stored as for aspartate transaminase.
ORNITHINE CARBAMOYLTRANSFERASE

A new procedure was developed to distinguish pig and human ornithine carbamoyltransferase isoenzymes from liver extract.

\section{Tank buffer}

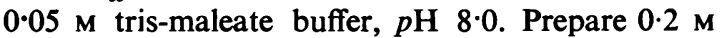
solution of tris-maleate $(24.2 \mathrm{~g}$ tris and $23.2 \mathrm{~g}$ maleic acid in 1 litre deionized water) and $0.2 \mathrm{M} \mathrm{NaOH}$ solution. To $50 \mathrm{ml}$ tris-maleate solution add $69 \mathrm{ml}$ $\mathrm{NaOH}$ solution. The $p \mathrm{H}$ should read 8.0. Dilute to $200 \mathrm{ml}$ with deionized water.

\section{Medium}

Cellulose acetate (Sartorius-Membranfilter GmbH, Germany) size $25 \times 160 \mathrm{~mm}$.

\section{Electrophoretic run}

One $\mathrm{mA} / \mathrm{cm}$ strip width for two hours.

\section{Enzyme locating reagent}

Prepare $0.05 \mathrm{M}$ tris-maleate buffer $p \mathrm{H} 7.2$ by adding $51 \mathrm{ml} \mathrm{NaOH}$ solution to $50 \mathrm{ml}$ tris-maleate solution and diluting to $200 \mathrm{ml}$ with deionized water. To $20 \mathrm{ml}$ of this buffer add $10 \mathrm{mg}$ lithium carbamoylphosphate (Sigma) and $60 \mathrm{mg}$ L-ornithine hydrochloride (Sigma). When dissolved add quickly dropwise $1 \mathrm{ml} 2 \%$ lead nitrate solution, stirring all the time. The solution is now slightly cloudy. Filter through a fluted Whatman no. 1 filter paper and collect filtrate in a small plastic tray. This substrate solution should be prepared just before the termination of electrophoresis. The cellulose acetate is cut to a suitable size and carefully floated face downwards on the substrate solution and allowed to incubate for about eight minutes at room temperature of about $25^{\circ} \mathrm{C}$.

The substrate becomes cloudy after about 10 minutes and it is important that the strip is removed before this occurs. The strip is rinsed in deionized water for about 10 seconds and then in $1 \%$ ammonium sulphide solution. Within 10 seconds distinct discrete bands of lead sulphide appear. The strip is now immersed in water to wash away the excess ammonium sulphide and can be left in water or dried between sheets of blotting paper in the dark.

\section{ALKALINE PHOSPHATASE}

The procedure is a modification of the method of Posen, Neale, Birkett, and Brudenell-Woods (1967).

\section{Tank buffer}

$0.125 \mathrm{M}$ tris- $\mathrm{HCl}, p \mathrm{H} 8.8$. Dissolve $15.143 \mathrm{~g}$ tris in about $800 \mathrm{ml}$ deionized water. Adjust the $p \mathrm{H}$ to $8 \cdot 8$ with concentrated hydrochloric acid. Make up to 1 litre with water. 


\section{Medium}

Cellogel, soaked for at least one hour in the tank buffer.

\section{Electrophoretic run}

$100 \mathrm{~V}$ for one and a half hours.

\section{Enzyme locating reagent}

Prepare freshly $20 \mathrm{mg} \alpha$-naphthylphosphate in $10 \mathrm{ml}$ $0.2 \mathrm{M}$ tris solution containing $0.01 \mathrm{M} \mathrm{MgSO}_{4}$, and $5 \mathrm{mg}$ Azoene Fast violet B salt $/ 5 \mathrm{ml}$ water. Mix both solutions and place a broad cellulose acetate strip (Celagram) into this. Drain off excess liquid and place the strip in a moist box. Electrophoresis should now terminate and after the Cellogel is cut to a suitable size, it is layered over the substrate-soaked cellulose acetate strip, face downwards, and incubated at $37^{\circ} \mathrm{C}$ for about 30 minutes, by which time reddish bands appear. The Cellogel is washed in water, in $5 \%$ acetic acid, and in water again, and will keep under water in the refrigerator.

\section{Results}

In every case it was possible to distinguish human from pig enzymes, as shown in Figures 1-8. A diagram of the distribution of lactate dehydrogenase

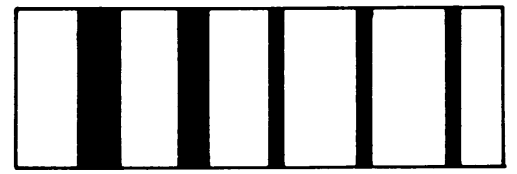

pig

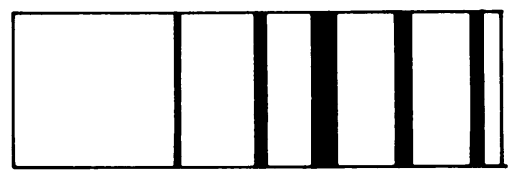

human and pig

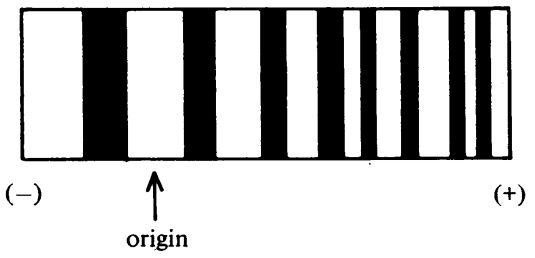

Fig. 1 Lactate dehydrogenase isoenzyme pattern of human and pig liver extract.

isoenzymes for human and pig liver extract is shown in Figure 1. As the individual isoenzymes in the liver in both species vary in such concentration, it was not possible to obtain a clear separation of all the isoenzymes, especially when a mixture of the human and

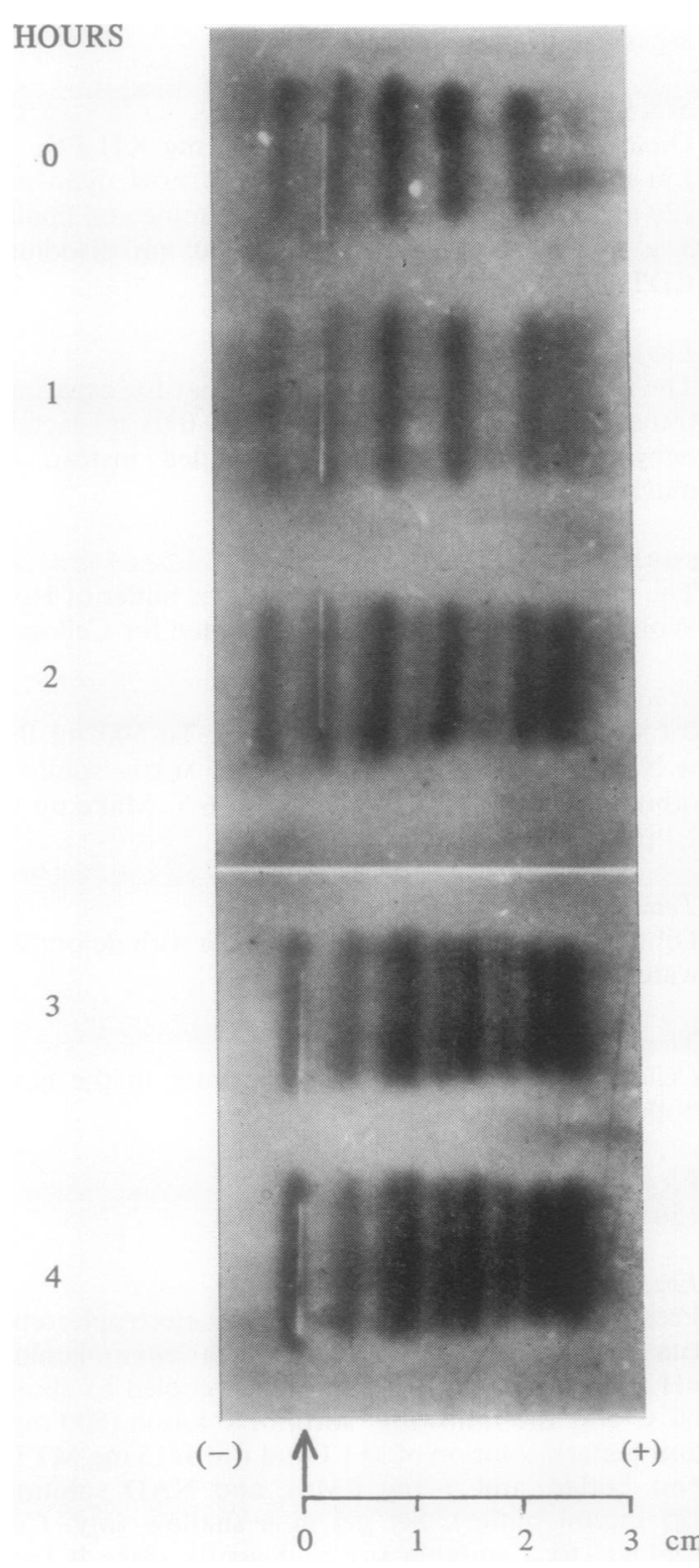

Fig. 2 Lactate dehydrogenase isoenzyme changes during an experimental pig liver perfusion stained by tetrazolium. 
human

pig

human and pig

Fig. 3.
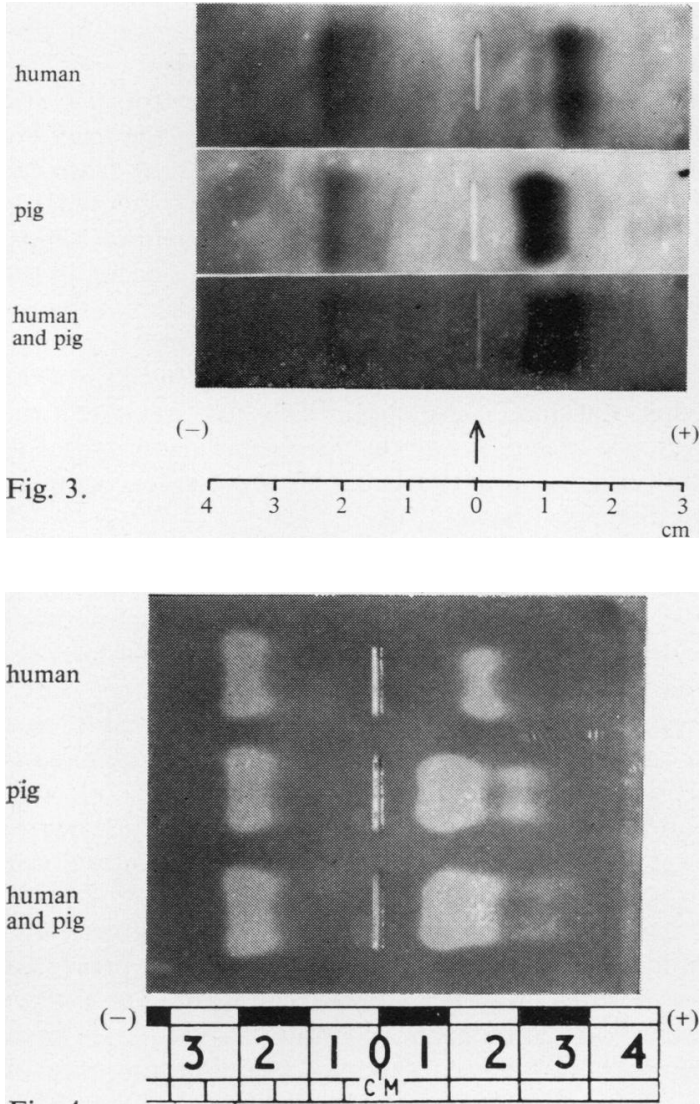

Fig. 4.

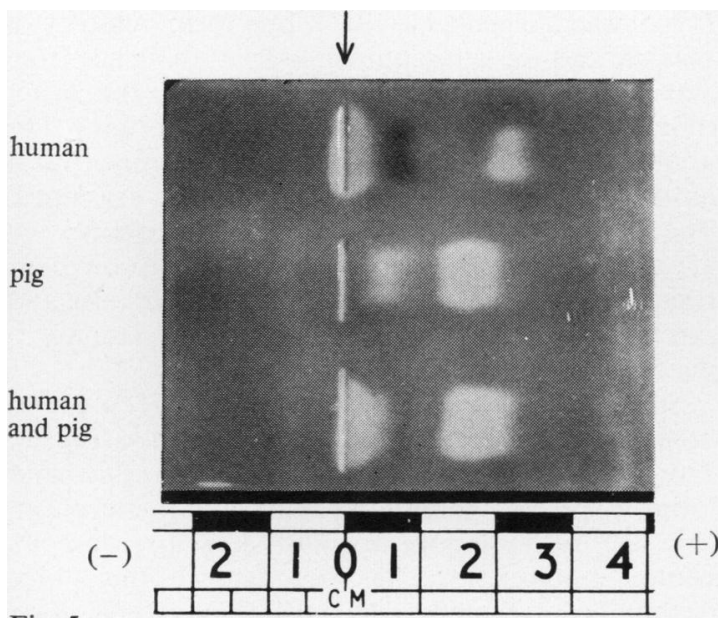

Fig. 5.

Fig. 3 Aspartate transaminase isoenzymes separated on Cellogel and stained by Fast violet $B$ salt.

Fig. 4 Aspartate transaminase isoenzymes separated on Cellogel and stained by reverse tetrazolium.

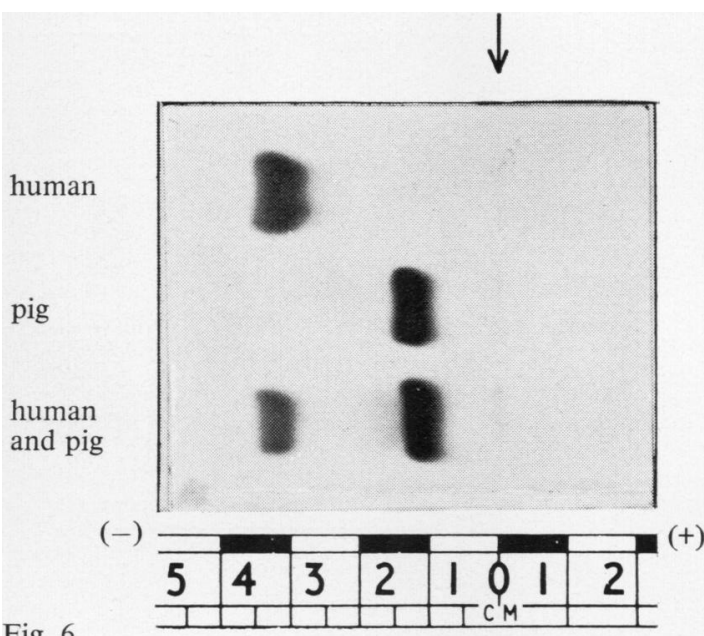

Fig. 6.

human

pig

human and pig

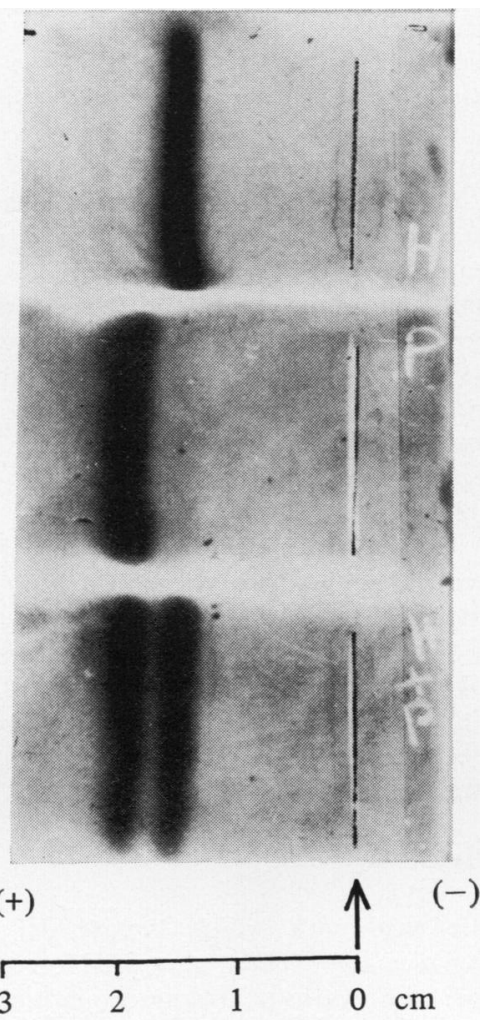

Fig. 7.

Fig. 5 Alanine transaminase isoenzymes separated on Cellogel and stained by reverse tetrazolium.

Fig. 6 Sorbitol dehydrogenase isoenzymes separated on Cellogel and stained by tetrazolium.

Fig. 7 Ornithine carbamoyltransferase isoenzymes separated on cellulose acetate strip and stained by lead substitution. Note that the anode is on the left. 


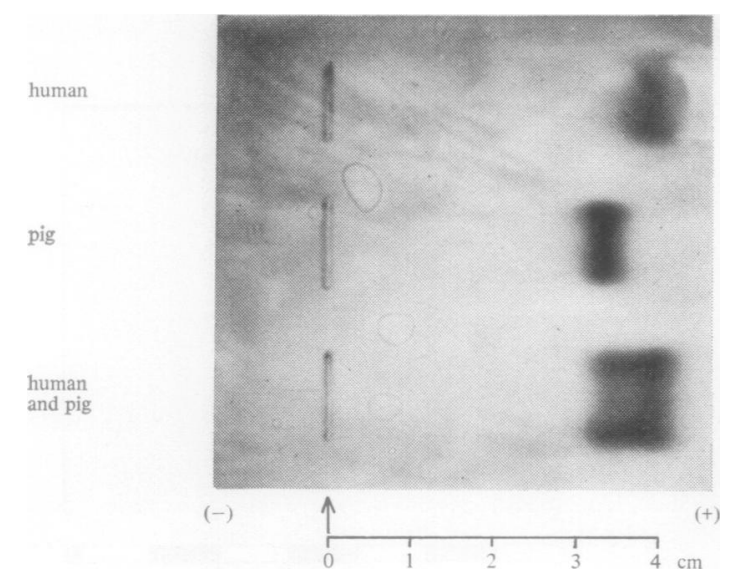

Fig. 8 Alkaline phosphatase isoenzymes separated on Cellogel and stained by Azoene Fast violet B salt.

pig liver extract was subjected to electrophoresis. However, good separation and differentiation were obtained with human and pig sera or with samples obtained after perfusion (Fig. 2).

The aspartate transaminase isoenzyme activity can be shown by two staining techniques. The direct staining method using Fast violet B salt (Fig. 3) has the advantage of being semi-quantitative. The reverse tetrazolium-staining technique (Fig. 4) appears to be more sensitive, especially for the cathodic band, but does not permit visual quantitation of the zone of enzyme activity: in addition, this technique is able to detect an extra anodic band in pig liver.

Alanine transaminase has been shown to exist in two molecular forms for both human and pig liver extract (Fig. 5). Only one molecular form is shown to exist for sorbitol dehydrogenase (Fig. 6), ornithine carbamoyltransferase (Fig. 7), and alkaline phosphatase (Fig. 8) in human and pig liver extract under the conditions in which the separation was carried out.

\section{Discussion}

The ease with which lactate dehydrogenase isoenzymes have been separated on cellulose acetate and the various fractions distinguishable from human and pig origin have permitted us to evaluate this enzyme change during both clinical and experimental perfusion. Taking an experimental perfusion as an example (Fig. 2), the first specimen, that of priming human blood, shows the normal five lactate dehydrogenase bands. The next specimen shows a trace of a faster moving lactate dehydrogenase band which becomes distinct later. Additional bands appear which come from the pig liver during the perfusion. By this system of electrophoresis, we can usually detect eight bands, three from the pig and five from the human source, though in the example shown a total of nine bands are seen, four from the pig. We have shown in fact that the perfused pig liver liberates all five lactate dehydrogenase bands, but because bands 4 and 5 from the pig occur in the same place in our system together with human bands 3 and 4 (see Fig. 1), we normally cannot see them. Bersohn, Kew, Rolle, Mieny, and Myburgh (1969), using starch gel electrophoresis, first reported the presence of pig lactate dehydrogenase isoenzymes in the sera of patients treated through extracorporeal pig liver perfusion.

Aspartate transaminase isoenzymes of human and pig are distinguishable only in the anodic (cytoplasmic) bands, while their cathodic (mitochondrial) bands have similar mobility and are not distinguishable (Fig. 3). This is rather fortunate as most raised aspartate transaminase levels are first encountered in the anodic band, and only when liver damage is gross will the cathodic band be seen electrophoretically. The priming blood and erythrocytes have hardly any cathodic aspartate transaminase and hence will not interfere.

An electrophoretic separation of alanine transaminase showing two isoenzyme bands is presented for the first time. Both human and pig liver extract show two bands each and both human bands have different mobilities to that of pig. The presence of two molecular forms of alanine transaminase have been suggested by Swick, Barnstein, and Stange (1965) and Ziegenbein (1966), one form being cytoplasmic and the other mitochondrial. Evidence from stability studies seems to suggest that the faster moving fraction is mitochondrial in origin. The application to perfusion studies of alanine transaminase isoenzyme changes has not been examined. The main reason for this is that the changes in alanine transaminase levels during perfusion have been slight compared to aspartate transaminase and this is due to the low level of alanine transaminase in pig liver tissue.

Sorbitol dehydrogenase isoenzymes of pig and human liver extract are easily distinguishable (Fig. 6). This system of separation, which gives only one band for each species, avoids the problem of polymorphism and fine resolution of sorbitol dehydrogenase by better techniques. It has been shown that three phenotypes are observed in pig (Hof, 1969) using starch gel electrophoresis. With the polymorphism in pig and possibly also in human liver, the differentiation of the human and pig enzyme fraction would be difficult and uncertain on starch gel. The proposed 
system which distinguishes the sorbitol dehydrogenase of human and pig has only recently been developed and has not been applied to clinical cases. Its application to experimental perfusion is not necessary. Any rise of sorbitol dehydrogenase above the basal priming blood must originate from enzymes liberated from damaged pig liver.

Human and pig ornithine carbamoyltransferase from liver extract both show one band each but have different mobility (Fig. 7). A mixture of both was distinguishable as two discrete bands using a new staining method which we have developed for cellulose acetate. However, it has not been possible to detect this enzyme in the perfusate and patient samples on cellulose acetate because of the relative low enzyme activity when compared to liver extract.

The separation of the isoenzymes of alkaline phosphatase of human and pig liver extract was also achieved. During both experimental and clinical perfusion the level of alkaline phosphatase has been noted to remain unchanged, suggesting that this enzyme is not readily released from the damaged pig liver. The separation of alkaline phosphatase of human and pig fractions is at present of theoretical interest.

J.E.B. is in receipt of a postgraduate training fellowship from the Government of Malaysia. We are grateful to Dr S. P. Parbhoo and the Department of Medicine, Royal Free Hospital, for their constant collaboration.

\section{References}

Abouna, G. M., Ashcroft, T., Hull, C., Hodson, A., Kirkley, J., and Walder, D. N. (1969). The assessment of function of the isolated perfused porcine liver. Brit. J. Surg., 56, 289-295.

Bersohn, I., Kew, M. C., Rolle, M., Mieny, C. J., and Myburgh, J. A. (1969). Porcine lactic dehydrogenase in the serum of patients treated by extracorporeal porcine liver perfusion. Brit. med.J., 2, 84-85.

Buttery, J. E., Parbhoo, S. P., and Baron, D. N. (1971). Serum enzyme and isoenzyme changes in the assessment of experimental and clinical extracorporeal pig liver perfusion. Clin. Sci., 41, 4P.

Eiseman, B. (1966). Treatment of hepatic coma by extracorporeal liver perfusion. Ann. roy. Coll. Surg. Engl., 38, 329-348.

Hof, J. O. (1969). Isoenzymes and population genetics of sorbit dehydrogenase in swine (Sus scrofa). Humangenetik., 7, 258-259.

Hof, J. O., Wolf, U., and Krone, W. (1969). Studies on isoenzymes of sorbitol dehydrogenase in some vertebrate species. Humangenetik., 8, 178-182.

Morton, R. K. (1955). Methods of extraction of enzymes from animal tissues. Meth. Enzymol., 1, 25-51.

Myers, R. C., and Van Remortel, H. (1968). The use of a reagent gel to locate LDH isoenzymes separated on cellulose acetate membranes. Clin. Chem., 14, 1131-1134.

Posen, S., Neale, F. C., Birkett, D. J., and Brudenell-Woods, J. (1967). Intestinal alkaline phosphatase in human serum. Amer. J. clin. Path., 48, 81-86.

Romel, W. C., and LaMancusa, S. J. (1965). Electrophoresis of glutamic oxalacetic transaminase in serum, beef heart and liver homogenates on cellulose acetate. Clin. Chem., 11, 131-136.

Swick, R. W., Barnstein, P. L., and Stange, J. L. (1965). The metabolism of mitochondrial proteins: distribution and characterisation of the isozymes of alanine aminotransferase in rat liver. J. biol. Chem., 240, 3334-3340.

Ziegenbein, R. (1966). Two different forms of glutamic pyruvic transaminase in rat heart and their intracellular localization. Nature (Lond.), 212, 935. 